\title{
SOUND PRODUCTION IN THE TERRITORIAL BEHAVIOUR OF THE CHURCHILL PETROCEPHALUS CATOSTOMA (MORMYRIDAE, TELEOSTEI) FROM THE UPPER ZAMBEZI RIVER
}

\author{
MICHAEL LAMML AND BERND KRAMER
}

Zoologisches Institut der Universität Regensburg, 93040 Regensburg, Germany

\begin{abstract}
This is the first description of vocalisations produced by the mormyrid species Petrocephalus catostoma from the Upper Zambezi River whilst defending a territory. Agonistic behavioural displays of a dominant male towards a conspecific, such as mutual circling or short attacks, were accompanied by characteristic tonal sounds, termed hoots. The mean hoot duration $(43 \pm \mathrm{SD} 1.8 \mathrm{~ms})$ was longer, and the fundamental frequency $(\mathrm{H} 1,180 \pm \mathrm{SD} 4.7 \mathrm{~Hz})$ lower, than in the closely related species Petrocephalus ballayi. P. catostoma vocalised hoots only during intraspecific agonistic interactions, especially those accompanying territorial conflict.
\end{abstract}

Key words: aggression, electric fish, sound production, territory, vocalisation

\section{INTRODUCTION}

Many fish species produce elaborate vocalisations during reproductive behaviour or territorial defence (Amorim 2006) that have been shown to function as signals in many cases (Ladich 2004). The African snoutfishes are well known for their electric sense, used for object location (Von der Emde \& Schwarz 2002) and communication (reviews, Moller 1995, Kramer 1996). Moreover, communication by acoustic signals seems more widespread within this fish family than known until recently (review, Crawford 1997). Recent observations document sound production not only in several species of the "strongly acoustic" genus Pollimyrus that vocalise species-specific courtship songs (Crawford et al. 1986, 1997a,b; Lamml \& Kramer 2005, 2006), but also in three allopatric populations within the Marcusenius macrolepidotus species

E-mails: LammlMichael@aol.com bernd.kramer@biologie.uni-regensburg.de 
complex (Lamml \& Kramer 2007) that have now been recognised as distinct species (Kramer et al. 2007). Within the genus Petrocephalus up to now only the species Petrocephalus ballayi from Lake Tumba (equatorial region of Zaire) was known to vocalise (Crawford 1997). Here we document vocalisations accompanying agonistic interactions by another mormyrid species, Petrocephalus catostoma, commonly known as the Churchill, from the Upper Zambezi River (see Kramer \& Van der Bank 2000 for a detailed description of this form of $P$. catostoma). A more thorough critical revision of the allopatric populations of $P$. catostoma is underway (Kramer et al., in preparation).

\section{METHODS}

Twelve Petrocephalus catostoma (Günther, 1866) (Figure 1) were caught in August 1994 in the Upper Zambezi River near Katima

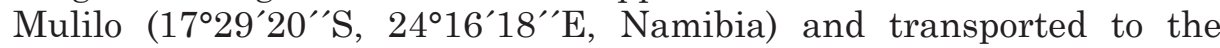
laboratory in Regensburg, Germany, by air. For the present study, we observed six males and one female [standard lengths (SL), 9.1$10.4 \mathrm{~cm}]$. Two males and one female were kept together in a 360litre aquarium with an external filter (Eheim model 2213). Stones and plants (Cryptocoryne affinis and Vesicularia dubyana) were offered for shelter. Water temperature was adjusted to $25^{\circ} \mathrm{C}$, and the L:D cycle was 12:12 hours. Animals were fed on chironomid larvae five times per week. Additional observations of two pairs of

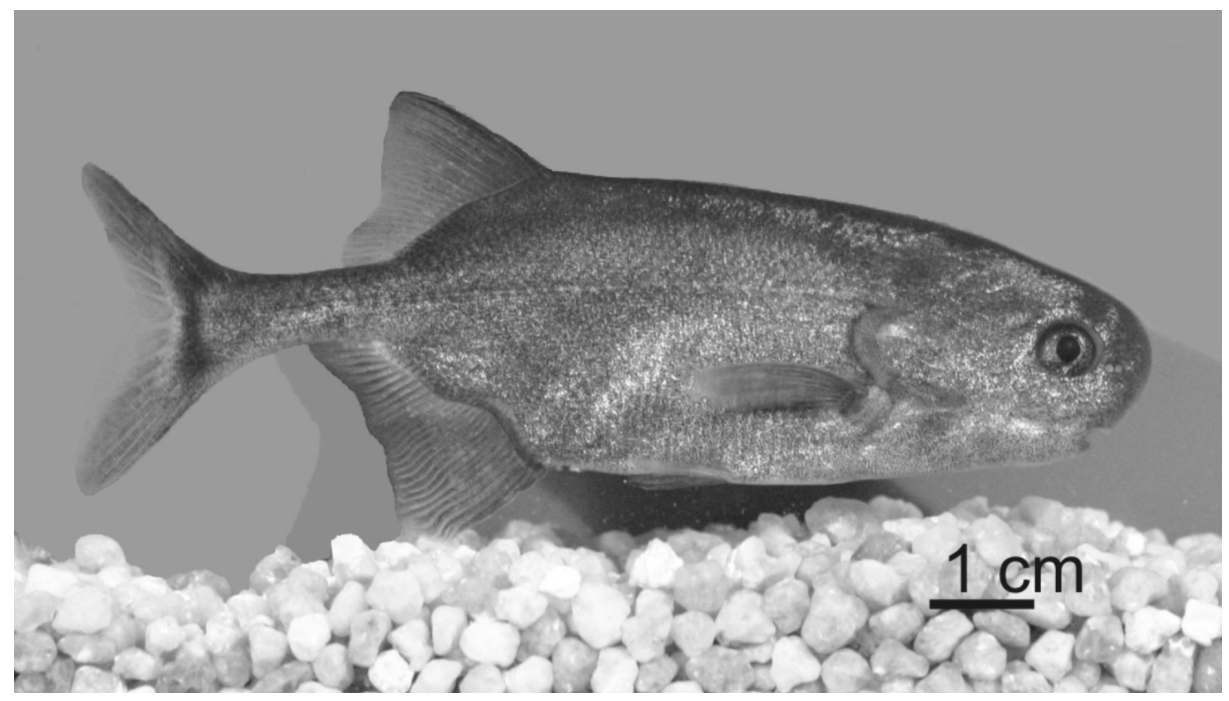

Figure 1. Photograph of a $P$. catostoma male $(9.2 \mathrm{~cm}$ SL) from the Upper Zambezi River. Specimens have a uniform silver-grey coloration. (SL = distance tip of snout to midbase of caudal fin). 
male $P$. catostoma were made under similar conditions but for an opaque plastic partition separating the highly aggressive fish from one another. In both $\delta \hat{~ p a i r s ~ w e ~ r e m o v e d ~ t h e ~ p a r t i t i o n ~ i m m e d i a t e l y ~}$ before the nocturnal observational period to allow the fish to show their unrestrained behaviour.

Fish behaviour was videotaped (Panasonic AG-7330 videorecorder, Hifi, S-VHS) during the daily feeding period shortly before dark in the $\widehat{\delta} \hat{\sigma}+$ group and during dark in both $\delta \hat{\delta}$ pairs, using infrared illumination with no visible light (model UF 500 FL, Derwent Systems, Cramlington, UK, $\lambda \geq 800 \mathrm{~nm}$ ) and an infraredsensitive camera (model FK 6990-IQ, Cohu, San Diego, CA, USA). Simultaneously, we recorded sounds with a hydrophone (Brüel \& Kjær, Model 8101, 1-125,000 Hz frequency response), positioned near the common territory boundary. Sounds were amplified with a measuring amplifier (Brüel \& Kjær, Model 2610, 2-200,000 Hz frequency response) and recorded on the audio-track of the videorecorder. To reduce low frequency noise, the amplified hydrophone output was bandpass-filtered $(40 \mathrm{~Hz}$ to $10000 \mathrm{~Hz}$ passband, linear phase response, -24 dB attenuation/ octave) using an electronic filter (Wavetek-Rockland, Model 452). Vocalisations were digitised at 48 $\mathrm{kHz}$ sampling rate and 16 bit resolution using the standard soundcard of an IBM-compatible computer (Pentium IV, $1.7 \mathrm{GHz}$ ), controlled by the software Avisoft-SASLabPro Version 4.33 (Avisoft, Bioacoustics, Berlin, Germany).

The animals vocalised only at a close distance from each other. Therefore, we were unable to assign vocalisations to a specific individual of a pair. To evaluate sound duration and number of sound pulses, we used the cursor and zoom-functions of Avisoft. Frequency parameters, such as fundamental frequency (H1), frequency of strongest intensity (peak-amplitude frequency, PAF) and frequency of additional harmonics, were estimated from amplitude spectra generated using Avisoft routines. Given the short duration of the hoot, the entire sound was used for the generation of amplitude spectra (frequency resolution: $1.46-2.9 \mathrm{~Hz}$ ). Due to the downward frequency modulation observed during a hoot, the harmonics are wider than the theoretical spectral lines (Fig. 2C). This effect, however, is less prominent for the first few harmonics that are presumably the more relevant ones. Hoot pulse period was measured by visually estimating the period between adjacent peaks of hoot pulses. We excluded overlapping hoots from the analysis. To determine the absolute sound pressure level (SPL) of vocalisations generated at about $10 \mathrm{~cm}$ distance from the hydrophone we read the relative SPL off the measuring amplifier and calculated the absolute values $(\mathrm{dB}$ re: $1 \mu \mathrm{Pa}$ ) based on the sensitivity of the hydrophone. 


\section{RESULTS}

Two male and one female $P$. catostoma that had been kept together in the same aquarium for months showed strong territoriality and defended stable territories, as described in detail by Scheffel (2006) for the same individuals. During the daily feeding period an individual (the subdominant male or the female) sometimes ventured into the dominant male's territory in pursuit of an extra chironomid larvae. The dominant male aggressively chased away both invaders from his territory. Territory defence behaviour at the common border consisted of mutual circling, alternating with short, darting attacks of the dominant male against his opponent. It was during these agonistic interactions that we recorded short sounds of tonal quality, so-called hoots (Figure 2, term adopted from Crawford et al. 1986 for Pollimyrus adspersus). These observations of aggressive encounters in

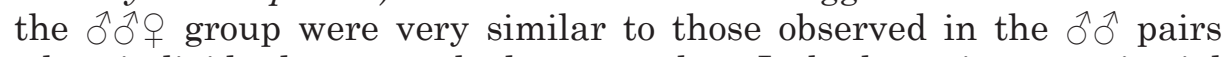
when individuals approached one another. In both settings, territorial disputes led to intense fighting correlated with many hoot sounds.

Hoots are very loud sounds, and, in a quiet environment, are audible to a human listener without any electronic gear (absolute SPL about $135 \mathrm{~dB}$ re: $1 \mu \mathrm{Pa}$ at a hydrophone-fish distance of about $10 \mathrm{~cm}$ ). Figure 2 shows a typical hoot and its acoustic characteristics. The hoot oscillogram displays a short burst consisting of 416 strong acoustic pulses separated by weak sinusoidal oscillations (Figure 2A-A') with a mean total hoot duration of $43 \pm \mathrm{SD} 1.8 \mathrm{~ms}$. Hoots showed spectral energy from about $100 \mathrm{~Hz}$ to more than 2000 $\mathrm{Hz}$ distributed over several harmonics (sonogram in Figure 2B). The fundamental frequency $(\mathrm{H} 1)$ at a mean $180 \pm \mathrm{SD} 4.7 \mathrm{~Hz}$ was not always the component of strongest intensity (PAF, see amplitude spectrum in Figure 2C). Additional harmonics occurred at $358 \pm$ SD $9.2 \mathrm{~Hz}(\mathrm{H} 2), 543 \pm \mathrm{SD} 17.1 \mathrm{~Hz}(\mathrm{H} 3)$, and at higher frequencies. Table 1 summarises the characteristics of the hoot sounds produced by the three groups of fish.

\section{DISCUSSION}

The present observations clearly demonstrate sound production in yet another mormyrid species, Petrocephalus catostoma from the Upper Zambezi River, during agonistic interactions. The mormyrid species Pollimyrus adspersus (Crawford et al. 1986), Pollimyrus isidori (Crawford et al. 1997a), Petrocephalus ballayi (Crawford 1997), and Marcusenius cf. macrolepidotus (Lamml \& Kramer 2007), representing, in addition to $M$. macrolepidotus, the new species $M$. altisambesi and the resurrected species $M$. pongolensis (recognised by Kramer et al. 2007), generate similar tonal sounds of short duration, termed hoots, during agonistic encounters. 


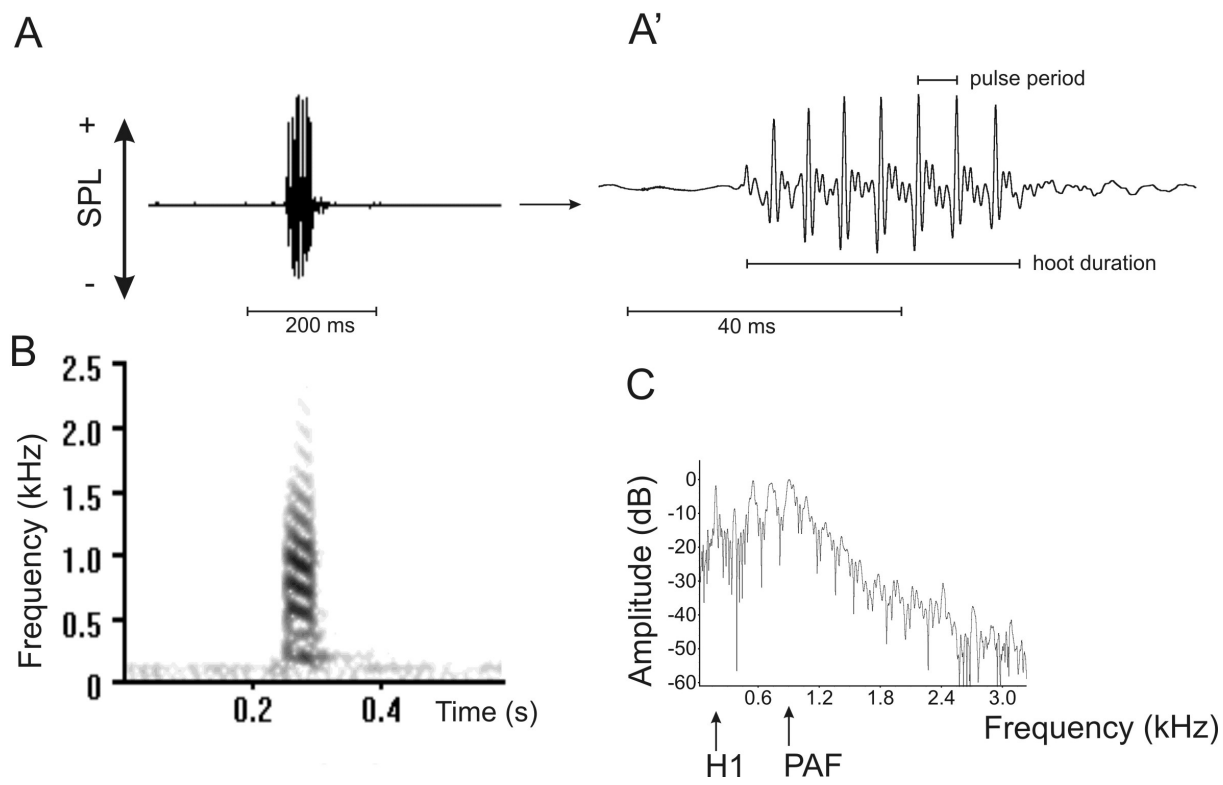

Figure 2. Temporal and spectral characteristics of the hoot. (A-A') Oscillogram of a hoot at low and high temporal resolution. (B) Sonogram (frequency resolution, $20 \mathrm{~Hz}$; temporal resolution, $3.2 \mathrm{~ms}$ ) and (C) amplitude spectrum for the same hoot. Note the multi-harmonic spectral structure. The frequency of strongest intensity (PAF) at $910 \mathrm{~Hz}$ corresponds approximately to the 5th harmonic in this particular hoot (H1 at $187 \mathrm{~Hz}$ in the hoot shown). Amplitude spectrum: frequency resolution $2.9 \mathrm{~Hz}$.

Many fish species generate sounds during competitive feeding, for example the grey gurnard, Eutrigla gurnardus (Amorim et. al.

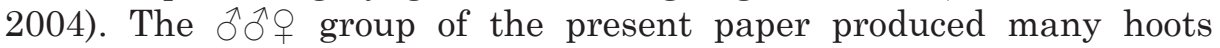
during agonistic encounters when being fed. By contrast, the $\widehat{\delta} \delta^{\lambda}$ $P$. catostoma pairs produced hoots during interactions that were correlated with agonistic territorial behaviour rather than feeding, an ethological context that had already been suggested for the hoots of P. ballayi by Crawford (1997).

Both P. catostoma and P. ballayi hoots are much louder (135 $\mathrm{dB}$ re: $1 \mu \mathrm{Pa}$ in $P$. catostoma; $130 \mathrm{~dB}$ re: $1 \mu \mathrm{Pa}$ in $P$. ballayi) than those of the other mormyrid species (e.g. $109 \mathrm{~dB}$ re: $1 \mu \mathrm{Pa}$ in three M. macrolepidotus-complex species Lamml \& Kramer 2007). Moreover, $P$. catostoma hoots differed from those of its congener P. ballayi by their longer duration (mean $43 \pm \mathrm{SD} 1.8 \mathrm{~ms}$ vs. $30 \mathrm{~ms}$; SD not given) and their lower first harmonic $(180 \pm \mathrm{SD} 4.7 \mathrm{~Hz}$ vs. $215 \pm 21 \mathrm{~Hz})$. Additionally, up to three harmonics were present in P. ballayi hoots (Crawford 1997) whereas the hoots of $P$. catostoma exhibited a multiharmonic spectral distribution. The mechanism of sound production 
Hoot characteristics of $P$. catostoma from the Upper Zambezi River. N=10 vocalisations during agonistic interactions within one $\hat{\delta} \hat{\partial} q$ group and in two $\hat{\delta} \hat{\sigma}$ pairs. All sounds were passband-filtered at $40 \mathrm{~Hz}-10000 \mathrm{~Hz}$. Water temperature: 24.4-25.2 ${ }^{\circ} \mathrm{C}$. H1, first harmonic or fundamental, H2, second harmonic, etc.

\begin{tabular}{|c|c|c|c|c|c|c|c|}
\hline & $\begin{array}{l}\text { Hoot } \\
\text { duration } \\
\quad(\mathrm{ms})\end{array}$ & $\begin{array}{l}\text { PAF } \\
(\mathrm{Hz})\end{array}$ & $\begin{array}{l}\mathrm{H} 1 \\
(\mathrm{~Hz})\end{array}$ & $\begin{array}{l}\mathrm{H} 2 \\
(\mathrm{~Hz})\end{array}$ & $\begin{array}{l}\mathrm{H} 3 \\
(\mathrm{~Hz})\end{array}$ & $\begin{array}{l}\text { Number } \\
\text { of } \\
\text { acoustic } \\
\text { pulses* } \\
\text { per hoot }\end{array}$ & $\begin{array}{l}\text { Pulse } \\
\text { period } \\
(\mathrm{ms})\end{array}$ \\
\hline \multicolumn{8}{|l|}{$\begin{array}{l}\text { Male } 1(9.6 \mathrm{~cm} \mathrm{SL}) \\
\text { Male } 2(10.1 \mathrm{~cm} \mathrm{SL}) \\
\text { Female } 1(10.4 \mathrm{~cm} \mathrm{SL})\end{array}$} \\
\hline $\begin{array}{l}\text { Mean/ Median* } \\
\text { Minimum } \\
\text { Maximum } \\
\text { Standard deviation (SD) }\end{array}$ & $\begin{array}{l}45.3 \\
22.8 \\
74.5 \\
16.9\end{array}$ & $\begin{array}{r}185 \\
176 \\
193 \\
6.5\end{array}$ & $\begin{array}{r}185 \\
176 \\
193 \\
6.5\end{array}$ & $\begin{array}{c}368 \\
346 \\
398 \\
15.8\end{array}$ & $\begin{array}{c}559 \\
542 \\
585 \\
14.8\end{array}$ & $\begin{array}{l}6.5^{*} \\
4 \\
16 \\
2.75^{*}\end{array}$ & $\begin{array}{l}5.28 \\
5.2 \\
5.5 \\
0.13\end{array}$ \\
\hline \multicolumn{8}{|l|}{$\begin{array}{l}\text { Male } 3(9.1 \mathrm{~cm} \mathrm{SL}) \\
\text { Male } 4(9.3 \mathrm{~cm} \mathrm{SL})\end{array}$} \\
\hline $\begin{array}{l}\text { Mean/ Median* } \\
\text { Minimum } \\
\text { Maximum } \\
\text { Standard deviation (SD) }\end{array}$ & $\begin{array}{l}44.5 \\
33.2 \\
54.6 \\
8.06\end{array}$ & $\begin{array}{l}416 \\
161 \\
674 \\
161\end{array}$ & $\begin{array}{l}175 \\
161 \\
197 \\
12.6\end{array}$ & $\begin{array}{l}349 \\
333 \\
379 \\
18.6\end{array}$ & $\begin{array}{l}525 \\
499 \\
576 \\
29.6\end{array}$ & $\begin{array}{l}7.5^{*} \\
6 \\
9 \\
1.0^{*}\end{array}$ & $\begin{array}{l}5.7 \\
5 \\
5.95 \\
0.35\end{array}$ \\
\hline \multicolumn{8}{|l|}{$\begin{array}{l}\text { Male } 5(9.8 \mathrm{~cm} \mathrm{SL}) \\
\text { Male } 6(9.2 \mathrm{~cm} \mathrm{SL})\end{array}$} \\
\hline $\begin{array}{l}\text { Mean/ Median* } \\
\text { Minimum } \\
\text { Maximum } \\
\text { Standard deviation (SD) }\end{array}$ & $\begin{array}{l}41.7 \\
33.4 \\
57.1 \\
6.5\end{array}$ & $\begin{array}{l}436 \\
176 \\
930 \\
304\end{array}$ & $\begin{array}{l}181 \\
176 \\
187 \\
4.9\end{array}$ & $\begin{array}{l}358 \\
352 \\
364 \\
4.7\end{array}$ & $\begin{array}{l}544 \\
525 \\
569 \\
13.3\end{array}$ & $\begin{array}{l}8.0^{*} \\
6 \\
11 \\
0.5^{*}\end{array}$ & $\begin{array}{l}5.4 \\
5.2 \\
5.7 \\
0.14\end{array}$ \\
\hline
\end{tabular}

* Median and semi-interquartile ranges for count measures.

in $P$. catostoma is unknown. However, the sound structure seems to point to an extremely fast swimbladder drumming mechanism as demonstrated for the courtship songs of male Pollimyrus adspersus by Crawford \& Huang (1999). Differences either in body size or in the sound generating or resonant structures might be the proximate cause for the frequency differences between the two Petrocephalus species.

The signal value of hoots is unstudied at present, but it is clear that in $P$. catostoma hoots accompany threatening behaviour. It is unknown at present whether or not EOD production is arrested during hoot vocalisations, as observed in two parapatric Dwarf Stonebasher species, Pollimyrus castelnaui and $P$. marianne, when vocalising their 
long courtship songs (Baier \& Kramer 2007). Petrocephalus is a basal clade within the family Mormyridae and our observation strengthens the view of vocalisation representing a plesiomorphic trait for this family. A growing number of mormyrids discovered vocalising during intense social behaviours indicate that we are bound for more important discoveries in the communication of this group of weakly electric fish.

\section{ACKNOWLEDGEMENTS}

We thank Lew Scheepers (deceased), Chief Scientist Caprivi, The Ministry of Nature Conservation and Tourism, Namibia, and F. H. van der Bank, University of Johannesburg, Kingsway Campus, SA, for catching and sending the live fish. This work was supported by the Deutsche Forschungsgemeinschaft (DFG), grants Kr446/10-4 and $\mathrm{Kr} 446 / 10-5$.

\section{REFERENCES}

Amorim, M. C. P., Stratoudakis, Y. \& Hawkins, A. D. (2004). Sound production during competitive feeding in the grey gurnard. J. Fish. Biol., 65, 182-194.

Amorim, M. C. P. (2006). Diversity of sound production in fish. In Communication in Fishes (Ed. by F. Ladich, S. P. Collins, P. Moller \& B. G. Kapoor), pp 71-105. Enfield, New Hampshire: Science Publishers.

Baier, B. \& Kramer, B. (2007). Electric communication in the courtship and spawning of two sibling species of dwarf stonebasher from southern Africa, Pollimyrus castelnaui and P. marianne (Mormyridae, Teleostei): evidence for a non speciesspecific communication code? Behav., 144, 115-142.

Crawford, J. D. (1997). Hearing and acoustic communication in mormyrid electric fishes. Mar. Fresh. Behav. Physiol., 29, 65-86.

Crawford, J. D. \& Huang, X. (1999). Communication signals and sound production mechanisms of mormyrid electric fish. J. Exp. Biol., 202, 1417-1426.

Crawford, J. D., Hagedorn, M. \& Hopkins, C. D. (1986). Acoustic communication in an electric fish Pollimyrus isidori (Mormyridae). J. Comp. Physiol. A, 159, 297-310.

Crawford, J. D., Jacob, P. \& Bénech, V. (1997a). Sound production and reproductive ecology of strongly acoustic fish in Africa: Pollimyrus isidori, Mormyridae. Behaviour, 134, 677-725.

Crawford, J. D., Cook, A. P. \& Heberlein, A. S. (1997b). Bioacoustic behavior of African fishes (Mormyridae): Potential cues for species and individual recognition in Pollimyrus. J. Acoust. Soc. Am. 102, 1200-1212.

Kramer, B. (1995). Electroreception and Communication in Fishes. Progress in Zoology. Vol. 42. Stuttgart: Gustav Fischer.

Kramer, B. \& Van der Bank, F. H. (2000). The southern churchill, Petrocephalus wesselsi, a new species of mormyrid from South Africa defined by electric organ discharges, genetics, and morphology. Environ. Biol. Fishes., 59, 393-413.

Kramer, B., Skelton, P., Van der Bank, F. H. \& Wink, M. (2007). Allopatric differentiation in the Marcusenius macrolepidotus species complex in southern and eastern Africa: the resurrection of $M$. pongolensis and $M$. angolensis, and the description of two new species (Mormyridae, Teleostei). J. Nat. Hist., 41, 647-708. 
Ladich, F. (2004). Sound production and acoustic communication. In The Senses of Fish. Adaptations for the Reception of Natural Stimuli (Ed. by G. von der Emde, J. Mogdans \& B. G. Kapoor), pp. 210-230. Boston Dordrecht: Kluwer Academic Publishers; New Delhi Chennai: Narosa Publishing House.

Lamml, M. \& Kramer, B. (2005). Sound production in the reproductive behaviour of the weakly electric fish Pollimyrus marianne Kramer et al. 2003 (Mormyridae, Teleostei). Bioacoustics, 15, 51-78.

Lamml, M. \& Kramer, B. (2006). Differentiation of courtship songs in parapatric sibling species of dwarf stonebashers from southern Africa (Mormyridae, Teleostei). Behaviour, 143, 783-810.

Lamml, M. \& Kramer, B. (2007). Allopatric differentiation in the acoustic communication of a weakly electric fish from southern Africa, Marcusenius macrolepidotus (Mormyridae, Teleostei). Behav. Ecol. Sociobiol., 61, 385-399.

Moller, P. (1995). Electric Fishes: History and Behaviour. London: Chapman and Hall.

Scheffel, A. \& Kramer, B. (2006). Intra- and interspecific electrocommunication among sympatric mormyrids in the Upper Zambzi River. In Communication in Fishes (Ed. by F. Ladich, S.P. Collin, P. Moller \& B.G. Kapoor) pp. 733-751. Enfield, New Hampshire, USA: Science Publishers Inc.

Von der Emde, G. \& Schwarz, S. (2002). Imaging of objects through active electrolocation in Gnathonemus petersii. Journal Physiology-Paris, 96, 431-444.

Received 27 August 2007, revised 23 February 2008 and accepted 26 February 2008 